\title{
Erratum to: Induced resistance in potato to Phytophthora infestans - effects of BABA in greenhouse and field tests with different potato varieties
}

Erland Liljeroth • Therése Bengtsson • Lars Wiik • Erik Andreasson

Published online: 23 March 2010

(C) KNPV 2010

Erratum to: Eur J Plant Pathol

DOI 10.1007/s10658-010-9582-4

The name of the organism "Phytphthora infestans" now wrong should be: Phytophthora infestans

The online version of the original article can be found under http://dx.doi.org/10.1007/s10658-010-9582-4.

E. Liljeroth $(\bowtie) \cdot T$. Bengtsson $\cdot$ L. Wiik $\cdot$ E. Andreasson

Department of Plant Protection Biology,

Swedish University of Agricultural Sciences,

P.O. Box 102, 23053 Alnarp, Sweden

e-mail: Erland.Liljeroth@1tj.slu.se 